\title{
Psicologia Acadêmica da Religião no Brasil: história, resultados e perspectivas
}

\author{
Academic Psychology of Religion in Brazil: \\ history, achievements and prospects
}

\section{Geraldo José de Paiva*}

Universidade de São Paulo, São Paulo, SP, Brasil

\section{Resumo}

Apresenta-se o estado atual da Psicologia acadêmica da Religião no Brasil, em sua história, resultados e perspectivas, com ênfase na dimensão institucional. Traça-se breve histórico das atividades ligadas à Psicologia da Religião no meio universitário: criação da Psicologia da Religião no Brasil como Sociedade Brasileira de Psicologia Religiosa, oferta de disciplinas na pós-graduação e na graduação, constituição do Grupo de Trabalho da Anpepp "Psicologia \& Religião". Apontam-se os resultados dessas atividades: publicações na Revista de Psicologia Normal e Patológica e em outros periódicos, dissertações e teses no tema, Seminários bienais do GT, participação do GT em eventos nacionais e internacionais, criação do Laboratório de Psicologia Social

GJP: Doutor em Psicologia, e-mail:gidpaiva@usp.br 
da Religião, expansão da pesquisa em instituições de ensino superior. Indicam-se algumas perspectivas: ampliação da oferta da disciplina, estabelecimento de rede de pesquisadores, inclusão de novos tópicos de pesquisa, expansão de contatos interdisciplinares, filiação à International Association for the Psychology of Religion, tradução de obras de referência e colaboração com as áreas de psicologia social, escolar e clínica em tópicos que incluam a religião.

Palavras-chave: Psicologia Acadêmica da Religião. Senso Religioso. Saúde e identidade religiosa. Fé e terapia.

\section{Abstract}

The academic Psychology of Religion (PR) in Brazil is examined in its history, achievements and perspectives, with emphasis on its institutional dimension. Its history began as an early Association around the Catholic University of São Paulo, as the offering of post-graduate and graduate disciplines, as a Laboratory, and as a Working Group (WG), belonging to the National Association for Research and Post-Graduation in Psychology. Its accomplishments are ordered along its history, with emphasis on the empirical and theoretical research, theses and dissertations in post-graduate programs, national Seminaries on PR, participation of the WG in national and international events, and its spreading in public and private universities. Its prospects cover the following topics: having the Psychology programs offering PR, developing a network among the national researchers in PR, enlarging the scope of PR's subject matters, having an interdisciplinary approach, increasing international contact, especially through IAPR, translating fundamental texts into Portuguese, helping clinical, social and school psychologists in psycho-religious matters.

Keywords: Academic Psychology of Religion. Religious Sense Healt and religious identity. Faith and therapy. 


\section{Introdução}

A frase "Psicologia da Religião" é um atalho para evitar o enunciado completo, a saber, Psicologia do comportamento religioso. É, de fato, com tal comportamento, que lida a ciência da Psicologia, abstendo-se metodologicamente, desde Flournoy (1902), de qualquer afirmação ou negação relativa à existência do transcendente, que está implicado na religião. No artigo será utilizado "Psicologia da Religião" no sentido exposto. Serão apresentados, sucessivamente, a História, os Resultados e as Perspectivas da Psicologia acadêmica da Religião no Brasil, com ênfase em sua dimensão institucional, isto é, sede em Universidade ou Faculdade, ensino e pesquisa em Psicologia da Religião, participação de eventos nacionais e internacionais da área. Não se desconhece a aproximação da Psicologia da Religião com o atendimento clínico, nem a abordagem junguiana ou freudiana às relações entre Religião e Psique, objeto, esta última, de levantamento crítico anterior (PAIVA, et al., 2009), mas optamos por apresentar as pesquisas realizadas no âmbito institucional acadêmico.

\section{História}

A Psicologia da Religião já estava estabelecida na Europa e nos Estados Unidos quando despertou interesse acadêmico no Brasil. De fato, na Europa a Escola de Dorpat já no início do século XX havia constituído o estudo do comportamento religioso como área legítima da Psicologia. Nos Estados Unidos, na mesma época, Stanley Hall e William James lançavam a base sólida da investigação psicológica do comportamento voltado para a religião (PAIVA, 1990; 2004). No Brasil, o estudo psicológico propriamente científico só teve início na década de 1960 com um grupo de interessados, de diversas especialidades, que se reuniam na PUC de São Paulo (VALLE, 2015). A esse grupo pertenciam também alguns psicólogos e psicanalistas de formação europeia, dentre os quais Alberto Abib Andery, Theodorus van Kolck, Odilon de Mello Franco Filho, fundou, em 1962, a Sociedade Brasileira de Psicologia 
Religiosa (Revista de Psicologia Normal e Patológica, 1965; ANDERY, 2001). Como informação histórica, vale fazer constar que anteriormente ao grupo chegou a existir no Instituto de Psicologia da PUCSP, um Departamento de Psicologia Religiosa, inspirado na Universidade Católica de Milão, organizado pelo médico e psicólogo italiano Enzo Azzi. Esse, contudo, não chegou a prosperar, devido às dificuldades financeiras da PUC, que não permitiam a contratação de professores (ANDERY, 2001). As pesquisas da Sociedade encontram-se registradas, em maior parte, na extinta Revista de Psicologia Normal e Patológica, da mesma Universidade. Um dado inesperado dessas primeiras publicações é o de que grande parte delas era de índole experimental, ao contrário do que se verificou em décadas posteriores até recentemente (PAIVA et al., 2009). Por volta do início dos anos 70 o grupo entendeu ser mais condizente com o momento nacional o estudo das comunidades e, abandonando a pesquisa em Psicologia da Religião, passou a produzir pesquisas e textos, que resultaram na Psicologia Comunitária. Recorda Andery (2001) que o Centro de Estudos da Religião (CER), por algum tempo localizado no Departamento de Sociologia da FFLCH, da USP, e o Instituto de Estudos da Religião (ISER), sediado no Rio de Janeiro, produziram posteriormente estudos em Psicologia da Religião, publicados em Religião e Sociedade, porém sem conexão com a Sociedade Brasileira de Psicologia Religiosa.

Em meados da década de 1980 começou a ser oferecida no Programa de Pós-Graduação em Psicologia Social, do Instituto de Psicologia da Universidade de São Paulo, uma disciplina voltada ao estudo do comportamento religioso. Essa disciplina ensejou o interesse pela pesquisa pós-graduada em Psicologia da Religião, de que resultaram dissertações e teses no mesmo Programa. Uma disciplina semelhante, de caráter optativo, foi, algum tempo depois, introduzida no curso de graduação de Psicologia. Em 2004 foi constituído, no âmbito do Departamento de Psicologia Social e do Trabalho, do IPUSP, um Laboratório de Psicologia Social da Religião (www.ip.usp.br//laboratorios/labpsirel>), ao qual se veio somar um grupo propedêutico de interessados. 
Outras iniciativas acadêmicas, em outros Programas do Instituto e em outras Universidades, como a PUCSP, a UFMG e a PUCCAMP, levaram, em 1998, à constituição de um Grupo de Trabalho denominado "Psicologia \& Religião", na Associação Nacional de Pesquisa e PósGraduação em Psicologia (ANPEPP). Graças a esse Grupo de Trabalho tornou-se possível coordenar as iniciativas esparsas da área, as expandindo e as consolidando. Com isso, o GT que congregava inicialmente pesquisadores de São Paulo e Minas, passou a integrar estudiosos de Brasília, do Rio Grande do Sul, do Paraná, do Rio de Janeiro e da Paraíba. Uma forma de consolidação do Grupo tem sido a realização, a cada dois anos, a partir de 1999, dos Seminários "Psicologia e Senso Religioso", realizados nos campi universitários, em Belo Horizonte, São Paulo, Campinas, Brasília, João Pessoa e Curitiba. Tais Seminários, com a presença e colaboração de pesquisadores nacionais e estrangeiros da Bélgica, França, Itália, Estados Unidos, Reino Unido e Alemanha, têm a maior parte das vezes focado um tema central, além de temas mais amplos de interesse para a Psicologia da Religião. O GT, por meio de seus membros, se tem feito também presente e atuante em várias reuniões da Sociedade Brasileira de Psicologia e, no âmbito internacional, nos encontros trienais do grupo European Psychologists of Religion e nos congressos bienais da International Association for the Psychology of Religion, além de em eventos universitários realizados em Oxford, Canterbury, Brest e Milão, na Europa, em Osaka e Sendai, no Japão, e em Syracuse, e South Bend, ambos nos Estados Unidos.

\section{Resultados}

Organizaremos em quatro secções os resultados conseguidos pela Psicologia acadêmica da Religião, conforme os núcleos de pesquisa que se foram estabelecendo no correr dos anos:

1. Em primeiro lugar, a Sociedade Brasileira de Psicologia Religiosa, estabelecida na PUC de São Paulo no ano de 1962. O veículo das publicações da Sociedade foi a Revista de Psicologia Normal e Patológica, da mesma PUC. Registram-se 13 artigos na década de 60, e um de 1956. Os 
temas desses artigos são, por ordem de frequência, o perfil psicológico de seminaristas e religiosos; a vivência religiosa em relação à estrutura psicológica e à personalidade; o conceito de psicologia "religiosa", sua relação com a espiritualidade e com a culpa moral. Note-se, de passagem, que na época vigorava a expressão "psicologia religiosa", em lugar de "psicologia da religião". A diferença da terminologia se deve, de um lado, ao uso do vocabulário francês em curso na Universidade de Lovaina de grande influência na PUCSP, de outro, à indiferenciação epistemológica do objeto dessa psicologia, que se veio determinando em anos posteriores no âmbito internacional.

2. As realizações vinculadas ao Departamento e ao Programa de Pós-Graduação em Psicologia Social do Instituto de Psicologia da Universidade de São Paulo, em segundo lugar, apontam para uma progressiva consolidação da pesquisa e do ensino em Psicologia da Religião. Primeiro passo nessa direção foi dado em meados da década de 1980, com a criação de uma disciplina de pós-graduação com o título Psicologia da Religião, a qual se acrescentou outra disciplina intitulada Psicologia Social da Religião. Intrigantemente, os alunos que se matriculavam nessas disciplinas provinham, na quase totalidade, de diversos cursos da Universidade, mas não do curso de Psicologia, para o qual, as disciplinas da Pós-Graduação tinham sido criadas. A situação foi se alterando com a oferta de uma disciplina optativa no curso de graduação, que pareceu corresponder a um interesse dos alunos não atendido pelas disciplinas ministradas no curso. Com o tempo foram realizadas pesquisas nos níveis de mestrado e doutorado, respectivamente em número de seis e de treze, até o presente. Em 2004 foi constituído, no âmbito do Departamento, o Laboratório de Psicologia Social da Religião, integrado por doutores e doutorandos, que tem produzido pesquisas, em sua quase totalidade amparadas pelo $\mathrm{CNPq}$, nos seguintes tópicos: crença paranormal religiosa e crença paranormal clássica; condições protopsíquicas de opção religiosa e científica; levantamento crítico da produção científica brasileira em Psicologia da Religião; ciência e religião em docentes/pesquisadores universitários brasileiros. Dado o interesse que a pesquisa psicológica da Religião tem despertado em muitas pessoas, foi criado, como decorrência do Laboratório, um Grupo de Estudos em 
Psicologia da Religião que oferece aos interessados um panorama histórico e teórico amplo dos temas pesquisados nessa especialidade.

3. Em terceiro lugar, a constituição, em 1998, do Grupo de Trabalho (GT) "Psicologia \& Religião" na Associação Nacional de Pesquisa e PósGraduação em Psicologia (ANPEPP) impulsionou em medida essencial o estudo da dimensão psicológica do comportamento religioso. O GT "Psicologia \& Religião" congregou pesquisadores que atuavam em várias Universidades, tornando compartilhados os estudos e as instituições. Com o tempo, ampliou-se o número de Universidades com representação no GT. Atualmente integram o GT pesquisadores da Universidade de São Paulo (Capital e Ribeirão Preto), das Universidades Federais de Minas Gerais, da Paraíba, do Rio Grande do Sul, da Universidade Metodista de São Bernardo do Campo, SP, das Universidades Católicas de São Paulo, Brasília e Paraná, da Universidade Paulista e da Escola Superior de Teologia, de São Leopoldo, RS. Cumpre notar que, em anos anteriores, o GT contou também com pesquisadores do Rio de Janeiro, da Universidade de Brasília e da PUC de Campinas. Desde sua fundação tem organizado Seminários bienais, que adquiriram, além de um caráter nacional mais amplo, um caráter internacional. Pesquisadores destacados da área têm participado dos Seminários, dentre os quais os professores Antoine Vergote e Jean-Marie Jaspard, de Leuven/Louvainla-Neuve, Mario Aletti, de Milão, Jeremy Carrette, de Canterbury, Miguel Farias, então de Oxford, Kenneth Pargament, de Bowling Green, Ohio, Kevin Ladd, de South Bend, Indiana, Denise Jodelet, da EHESS, de Paris, Charles Watters, da Rutgers University (PAIVA, 2001; PAIVA \& ZANGARI, 2004; ZANGARI \& PAIVA, em preparação; ARCURI \& ANCONA, 2007; FREITAS, PAIVA \& MORAES, 2013; AQUINO, 2016; ESPERANDIO, em preparação). Os Seminários têm tido, além de uma temática aberta, tópicos mais direcionados, tais como necessidade e desejo na religião, representação na religião, psicologia e espiritualidade, coping ou enfrentamento religioso, morte, psicologia e religião, desafios contemporâneos da Psicologia da Religião e interdisciplinaridade. Os papers apresentados nos Seminários têm originado a publicação de livros, alguns dos quais trazem o texto original em inglês ou francês, com a correspondente tradução em português. Até 2015 os livros publicados são 
os seguintes: Diante do Mistério: Psicologia e Senso Religioso (MASSIMI \& MAHFOUD, 1999); Entre Necessidade e Desejo: Diálogos da Psicologia com a Religião (PAIVA, 2001); A Representação na Religião: perspectivas psicológicas (PAIVA \& ZANGARI, 2004); Psicologia e Espiritualidade (AMATUZZI, 2005); Temas em Psicologia da Religião (ARCURI \& ANCONA-LOPEZ, 2007); Psicologia da Religião no mundo ocidental contemporâneo: Desafios da interdisciplinaridade, Vols. 1 e 2 (FREITAS, PAIVA \& MORAES, 2012); Morte, Psicologia e Religião (AQUINO, 2016). Em preparação encontram-se Enfrentamento (coping) religioso na saúde (ZANGARI \& PAIVA); Psicologia da Religião no Brasil: Pesquisa, Teoria e Prática (ESPERANDIO). Ao lado das publicações mais alentadas dos livros, numerosas contribuições dos membros do GT têm aparecido em periódicos científicos do país, como Psicologia: Reflexão e Crítica; Psicologia: Teoria e Pesquisa; Psicologia USP; Estudos de Psicologia (Campinas); Arquivos Brasileiros de Psicologia; Temas em Psicologia; Perspectiva Teológica; Revista de Ciência da Religião (REVER). Também em periódicos e livros do exterior, embora em muito menor número, têm sido registradas contribuições de membros do Grupo de Trabalho: Ricerche di Psicologia e Psychology of Religion e-Journal, na Itália; Studies in Religion/Sciences Religieuses, no Canadá; Archives for the Psychology of Religion, na Alemanha; Journal of Cultural and Religious Studies, nos Estados Unidos; Conflict Studies in the Humanities, no Japão; Belief and Unbelief: psychological perspectives, na Holanda. O GT tem-se feito representar nos Congressos internacionais de Psicologia da Religião, em Bari (2011), Lausanne (2013) e Istambul (2015), além de em Congressos anteriores dos European Psychologists of Religion, em particular no Congresso de Glasgow (2003), que recriou a International Association for the Psychology of Religion, como continuadora da Internationale Gesellschaft für Religionspsychologie, nela incorporando os European Psychologists. Eventos importantes, no Rio de Janeiro (2012) e em Oxford (2013), ligados às relações entre ciência e religião, em Canterbury (2013), em Brest (2012), em Dortmund (2014), em Verona (2000 e 2004), no Porto (2013) e em Milão (2013 e 2015), voltados para pesquisas atuais em Psicologia e Religião na Alemanha, 
em Portugal, na França, no Reino Unido e na Itália, contaram, igualmente, com a representação do Grupo.

4. Em quarto lugar, o interesse pelo estudo psicológico do comportamento religioso tem sido sustentado, embora por vezes de forma indireta, em outras Universidades e outros cursos. A PUC de Goiás manteve um Grupo de estudos denominado "Psicologia Social da Religião na Pós-Modernidade". A PUC de Minas Gerais publicou, na revista Interações -Cultura e Comunidade (CALDEIRA, R. et al. 2014), um dossiê intitulado "Psicologia e Religião". No Paraná, o grupo de estudos Núcleo Paranaense de Pesquisa em Religião (NUPPER) publicou recentemente, em sua revista, Relegens Threskeía, (OLIVEIRA,V.L. et al., 2015), uma inteira seção temática dedicada a Psicologia e Religião. Dois dossiês de Religião e Psicologia estão programados pela Revista de Estudos da Religião (REVER), para 2017, e pela Numen, da Universidade Federal de Juiz de Fora, para 2018. A Universidade Federal do Vale do São Francisco, em Pernambuco, conta com pesquisadora da religião popular à luz da psicanálise, e vice-versa. A Universidade de Brasília oferece, na graduação, a disciplina Psicologia da Religião. A PUC de São Paulo, além de incluir Psicologia da Religião no curso de pós-graduação em Ciência da Religião, tem produzido mestrados e doutorados relacionados com essa disciplina e organizou o excelente "Compêndio de Ciência da Religião” (PASSOS \& USARSKI, 2013), com ampla secção dedicada à Psicologia da Religião, coordenada por E. Valle. A Universidade Federal do Rio Grande do Sul, por meio de sua pós-graduação em Psicologia do Desenvolvimento, produziu, anteriormente à inclusão no GT, acurada validação da Escala de Coping Religioso-Espiritual de Pargament (Escala CRE) (PANZINI \& BANDEIRA, 2005), de grande impacto nos estudos brasileiros do enfrentamento religioso, e da Escala de Bem-estar Espiritual (Spiritual Well-Being Scale), de Paloutzian e Ellison (MARQUES, 2003). A PUC do Rio de Janeiro, graças a Monique Augras, contribuiu com publicações de valor, em Psicologia, acerca da religião popular e de cultos afro-brasileiros. Alguns autores independentes, embora ligados a instituições de ensino superior, também têm produzido trabalhos valiosos em Psicologia da Religião. Dentre eles Edênio Valle, com "Psicologia e Experiência Religiosa" (1998), Adriano Holanda (Org.), com "Psicologia, 
Religiosidade e Fenomenologia" (2004), V.A. Angerami-Camon (Org.), com "Espiritualidade e Prática Clínica” (2004), Karla Daniele Maciel Luz, com "Freud a Favor da Religião: como assim?" (2014), Ricardo Torri de Araújo, com "Deus analisado? Os católicos e Freud" (2014), e a tese de livre-docência de Francisco Lotufo Neto (1997), com "Psiquiatria e Religião - a prevalência de transtornos mentais em ministros religiosos". Na linha de Psiquiatria e Religião, caberia citar os estudos de Jorge W.F. Amaro, com "Psicoterapia e Religião" (1996), Raul Marino Jr., com "A Religião do Cérebro" (2005) e Paulo Dalgalarrondo, com "Religião, Psicopatologia e Saúde Mental” (2008). Alguns dos 12 cursos de pós-graduação em Ciência(s) da Religião, filiados à Associação Nacional de Pós-Graduação e Pesquisa em Teologia e Ciências da Religião (Anptecre, 2015), têm oferecido a disciplina "Psicologia da Religião" em sua grade curricular: as Universidades Federais de Juiz de Fora e da Paraíba de forma contínua; a Universidade Federal de Sergipe, de forma descontinuada; as Universidades Católicas de São Paulo, Minas Gerais e Pernambuco, de forma contínua; as Universidades Católicas de Campinas e de Goiás, de forma intermitente. Das oito Pós-Graduações em Teologia, apenas a Pontifícia Universidade Católica do Paraná ministra regularmente a disciplina. Registre-se, finalmente, a oferta da disciplina no curso de Graduação em Teologia da Universidade Presbiteriana Mackenzie e no curso de Graduação em Psicologia da Universidade Federal da Paraíba; da disciplina Teologia e Psicanálise, no curso de Graduação em Teologia da PUCRJ; da disciplina "Pesquisa em Espiritualidade e Saúde", no Programa de Pós-Graduação em Saúde, da Universidade Federal de Juiz de Fora.

Antes de concluir o tópico Resultados, é justo lembrar que o interesse pela Psicologia da Religião no Brasil conheceu algumas publicações esporádicas, independentes da criação da Sociedade na década de 1960. Em 1933, o jesuíta Leonel Franca publica "A Psicologia da Fé" (FRANCA, 1933), de índole, no entanto, mais filosófico-teológica do que psicológica. Em 1937, Afonso Rodrigues defende tese com o título Psicologia da Graça posteriormente publicada pelas Edições Loyola (RODRIGUES, 1983). De frei Damião Berge (BERGE, 1939) registra-se, em 1939, o artigo "A estrutura fundamental do sentimento religioso à 
luz da psicologia experimental”, e em 1942, “A estruturação psicológica da oração devota”. Em 1964, a Associação de Seminários Teológicos Evangélicos (ASTE) publica a tradução de "Psicologia da Religião", de Paul E. Johnson, e em 1971 a Casa Publicadora Batista edita "Psicologia da Religião", de Merval Rosa. No Rio de Janeiro, o jesuíta húngaro Antonius Benkö, ligado à PUCRJ (BENKÖ,1981), publica "Psicologia da Religião", que integra ampla pesquisa empírica realizada em 1975, intitulada "Aspectos psico-sociais [sic] da religiosidade no Estado da Guanabara".

\section{Perspectivas}

Que tarefas aguardam a Psicologia da Religião no Brasil nos próximos anos?

1. Parece-me que a tarefa principal é o estabelecimento, nos programas de pós-graduação, da disciplina Psicologia da Religião, que abra a possibilidade de pesquisa avançada nessa área, tendo como produtos dissertações e teses. Conjugada com essa tarefa está a oferta de uma disciplina, eletiva que seja, na graduação. É na graduação que se firmam os conceitos e os preconceitos em Psicologia, inclusive em relação à religião. Durante muito tempo, o silêncio a respeito do comportamento religioso, como algo fora do campo científico, ou a interpretação patológica desse comportamento como forma de neurose, impediram entre nós, uma aproximação objetiva e serena ao tema, e o atendimento a um interesse latente ou, por vezes, expresso dos alunos. Na Universidade de São Paulo, as disciplinas oferecidas na pós-graduação despertaram o interesse dos estudantes de Psicologia só após a oferta de uma disciplina optativa na graduação.

2. Uma segunda tarefa me parece a de estabelecer uma rede dos pesquisadores em Psicologia da Religião no Brasil para mútua informação e colaboração. Essa rede poderia ser criada e mantida pelo GT "Psicologia \& Religião", não só por sua estrutura já sedimentada como pelo fato de congregar pesquisadores de várias regiões do país. Esse meio colaborativo poderia, com o tempo, constituir uma Associação 
Nacional, que começaria como associação ou associações regionais. $\mathrm{Na}$ linha dessa ampliação, pode-se pensar na organização de um e-journal, sem prejuízo de publicações em periódicos nacionais de expressão.

3. Uma outra tarefa é a de ampliar os temas de pesquisa em Psicologia da Religião. Depois de elencar os temas mais presentes na pesquisa em seus primeiros cinquenta anos, os autores de "Psicologia da Religião: a produção em periódicos e livros" observaram:

a ausência quase completa de assuntos contemporâneos, como a negação da fé ou o ateísmo; a desfiliação institucional; o comportamento ligado a religiões não tradicionais nem hegemônicas, como o budismo, o islamismo, o judaísmo e as religiões indígenas; o lugar da experiência religiosa na sociedade pós-moderna ou pós-secular; e a religião na atividade profissional do psicólogo (PAIVA et al., 2009, p. 445).

A esses tópicos, carentes de adequada atenção, podem ser acrescentados outros, como a publicização da religião no Brasil, na perspectiva de José Casanova (CASANOVA, 1994; PAIVA, 2012), que tem levado a religião à política; o caráter cultural intrínseco às religiões (BELZEN, 2010); as raízes protopsíquicas e pré-culturais do comportamento religioso; o impacto dos vários meios digitais nesse comportamento.

4. Ainda outro desenvolvimento da Psicologia da Religião brasileira seria a ampliação dos contatos interdisciplinares ou pluridisciplinares. A Psicologia da Religião parece-me suficientemente consolidada teórica e metodologicamente para entrar em diálogo com outras disciplinas que se interessam pelo comportamento religioso (PAIVA, 2012).

5. Outra tarefa importante é a inserção da Psicologia da Religião brasileira no âmbito internacional, mediante a filiação dos pesquisadores à International Association for the Psychology of Religion. Essa filiação permite o estabelecimento de relações pessoais e institucionais com pesquisadores de outros países, que levem a pesquisas e publicações conjuntas. É imprescindível que, nessa interação, os pesquisadores brasileiros não se sintam subalternos, pois que mais de uma vez foi possível ouvir, dos pesquisadores estrangeiros, que temos muito a 
contribuir e até a ensinar. E parece-me importante, também, não importar problemas de outros países, em que pese a globalização. $\mathrm{Na}$ inserção internacional é aconselhável a interação decidida com parceiros da América Latina.

6. Tarefa mais modesta, mas de grande importância, deveria ser a de traduzir para o português textos significativos de Psicologia da Religião, como se fez com o livro de J.A.Belzen, "Para uma Psicologia Cultural da Religião". Dentre esses, além de outros recomendados pelos membros do GT, citaria, como sugestão, de A. Vergote, "Religion, Foi, Incroyance. Etude psychologique”; “Dette et Désir: deux axes chrétiens et la dérive pathologique" (traduzido para o inglês, mas sem a riqueza do original, como Guilt and Desire: Religious Attitudes and Their Pathological Derivatives); "Interprétation du langage religieux". De M. Aletti, "Percorsi di Psicologia della Religione alla luce della Psicoanalisi". De R.W. Hood, B. Spilka, B. Hunsberger \& R. Gorsuch, "The Psychology of Religion: An empirical approach”. De G. Theissen, traduzido do alemão, "Psychologie des premiers chrétiens". De K. Pargament, "The Psychology of Religion and Coping".

\section{Considerações finais}

O histórico da Psicologia acadêmica da Religião no Brasil e o registro de suas realizações permitem afirmar que as perspectivas traçadas para seu desenvolvimento são realistas. Limitamo-nos à dimensão propriamente acadêmica, isto é, de pesquisa, do tema. Porém, a pesquisa fecunda naturalmente atividades de extensão. Parecem sobressair, atualmente, três delas: a do atendimento clínico, a do cuidado com a saúde e a do ensino religioso na escola. Na realidade, nessas três atividades já se verifica a influência da pesquisa em Psicologia da Religião. O lugar da religião no atendimento clínico tem sido objeto destacado de interesse, sob forma, inclusive, de controvérsia. Uma contribuição exemplar da Psicologia é dada pelo Instituto Acolher, em São Paulo, que atende clinicamente a religiosos de várias filiações, com predominância de religiosos católicos (MASSIH, 2006; 2009). No campo da saúde, são numerosas as 
iniciativas em hospitais e no acompanhamento de processos de aculturação de (i)migrantes, ligadas principalmente ao coping, ou enfrentamento, que a religião oferece em situações difíceis (FREITAS, 2011, 2012, 2013, 2014). No âmbito escolar, em que o ensino religioso, confessional ou ecumênico/inter-religioso, necessita de esclarecimento conceitual e operacional, a Psicologia da Religião também se faz presente (PAIVA, 2006).

Embora o estudo do comportamento religioso não seja dos temas mais desenvolvidos da Psicologia brasileira e nem atraia multidões de interessados, tem-se firmado no meio acadêmico brasileiro com consistência, o que autoriza antever não só sua permanência como sua expansão nos próximos anos.

\section{Referências}

AMATUZZI, M. M. (Org.). Psicologia e espiritualidade. São Paulo: Paulus, 2005.

AMARO, J. W. F. Psicoterapia e religião. São Paulo: Lemos Editorial, 1996.

ANDERY, A. A. O conceito de psicologia religiosa. Revista de psicologia normal e patológica, v. 9, n. 3/4, p. 527-535, 1963.

ANDERY, A. A. Entrevista concedida a David Gaspar Ribeiro de Faria, Maria Luísa Trovato e Marisa Moura Verdade, do Laboratório de Psicologia Social da Religião, do IPUSP, aos 28 de agosto de 2001.

ANGERAMI-CAMON, V. A. (Org.) Espiritualidade e prática clínica. São Paulo: Thomson, 2004.

AQUINO, T. A. Morte, psicologia e religião. São Paulo: Fonte Editorial, 2016.

ARAÚJO, R. T. Deus analisado? Os católicos e Freud. São Paulo: Loyola, 2014.

ARCURI, I. G.; ANCONA-LÓPEZ (Orgs.). Temas em psicologia da religião. São Paulo: Vetor, 2007. 
Associação Nacional de Pós-Graduação e Pesquisa em Teologia e Ciências da Religião (ANPTECRE) Programas Associados e Docentes dos Programas de PósGraduação em Ciências da Religião e Teologia do Brasil, 2015. Disponível em: <http://www.anptecre.org.br/.>

BELZEN, J. A. Towards Cultural Psychology of Religion. Principles, Approaches, Applications. Nova York: Springer, 2010.

BENKÖ, A. Aspectos psico-sociais [sic] da religiosidade no Estado da Guanabara. Síntese, v. 2, n. 3, p. 49-103, 1975.

BENKÖ, A. Psicologia da Religião. São Paulo: Loyola, 1981.

BERGE, D. A estrutura fundamental do sentimento religioso à luz da psicologia experimental. A Ordem, v. 19, p. 125-150, 1939.

CASANOVA, J. Public Religions in the Modern World. Chicago: The University of Chicago Press, 1994.

DALGALARRONDO, P. Religião, Psicopatologia \& Saúde Mental. Porto Alegre: Artmed, 2008.

FLOURNOY, T. Les principes de la psychologie religieuse. Archives de Psychologie, v. 2, p. 33-57, 1902.

FRANCA, L. A Psicologia da Fé. Rio de Janeiro: Agir, 1933.

FREITAS, M. H. Religiosidade e Saúde: Experiência dos pacientes e percepção dos profissionais. Pistis \& Práxis, v. 6, p. 709-725, 2014.

FREITAS, M. H. Relações entre religiosidade e saúde mental em imigrantes: implicações para a prática psi. Psico-USF, v. 18, p. 437-444, 2013.

FREITAS, M. H. Religiosidade do imigrante: sintoma ou saúde? Boletim da Academia Paulista de Psicologia, v. 31, n. 81, p. 301-316, 2011.

FREITAS, M. H. \& PAIVA, G.J. Religiosidade e Cultura Contemporânea: desafios para a Psicologia. Brasília: Universa, 2012. 
FREITAS, M. H.; PAIVA, G. J.; MORAES, C. Psicologia da Religião no mundo ocidental contemporâneo. Desafios da interdisciplinaridade, v. I e II. Brasília: Universa, 2012.

HOLANDA, A. (Org.). Psicologia, religiosidade e fenomenologia. Campinas: Alínea, 2004.

SPILKA, B.; HUNSBERGER, B.; GORSUCH, R.; HOOD JUNIOR, R. W. The Psychology of Religion: an empirical approach. Nova York: The Guilford Press, 1996.

CALDEIRA, P. C. et al., Dossiê Psicologia e Religião, Interações: Cultura e Comunidade. v. 9, n. 16, p. 195-488, 2014. (Departamento de Ciências da Religião, PUC-MG)

JOHNSON, P. E. Psicologia da Religião. Trad. Carlos Chaves. São Paulo: ASTE, 1964.

LOTUFO NETO, F. Psiquiatria e religião - a prevalência de transtornos mentais entre ministros religiosos. Tese de Livre-Docência (Instituto de Psiquiatria) - Universidade de São Paulo, São Paulo, 1997.

LUZ, K. D. S. M. Freud a favor da religião: como assim? Curitiba: Prismas, 2014.

MARINO JUNIOR, R. A religião do cérebro: as novas descobertas da neurociência a respeito da fé humana. São Paulo: Ed.Gente, 2005.

MARQUES, L. F. A saúde e o bem-estar espiritual em adultos porto-alegrenses. Psicologia: ciência e profissão ,v. 23, p. 56-65, 2003.

MASSIH, E. A teoria do self dialógico e a psicologia cultural da religião na psicoterapia de religiosos. Revista de Estudos da Religião-REVER, v .9, p. 53-67, 2009.

MASSIH, E. Obsessão, culpa e espiritualidade em um religioso com comportamento pedófilo. Revista de Estudos da Religião-REVER, v. 6, p. 87-115, 2006.

MASSIMI, M.; MAHFOUD, M. (Orgs.). Diante do mistério: psicologia e senso religioso. São Paulo: Loyola, 1999. 
PAIVA, G. J. Psicologia da religião e sociologia da religião em diálogo. In: FREITAS, M. H.; PAIVA, G. J.; MORAES, C. (Orgs.). Psicologia da religião no mundo ocidental contemporâneo. Desafios da interdisciplinaridade, Brasília: Universa, v. II, p. 79-92, 2013.

PAIVA, G. J. Transmissão da cultura em comunidades religiosas contemporâneas: uma perspectiva psicológica. In: de Freitas, M. H.; de Paiva, G. J. (Orgs.). Religiosidade e cultura contemporânea: desafios para a psicologia. Brasília: Universa, p. 141-155, 2012.

PAIVA, G. J. O Estado e a educação religiosa: observações a partir da Psicologia. Psicologia: Teoria e Pesquisa, v. 22, p. 63-68, 2006.

PAIVA, G. J. (Org.). Entre necessidade e desejo: diálogos da psicologia com a religião. São Paulo: Loyola, 2001.

PAIVA, G. J. Psicologias da religião na Europa. Arquivos Brasileiros de Psicologia, v. 42, p. 88-99, 1990.

PAIVA, G. J. et al. Psicologia da religião no Brasil: a produção em periódicos e livros. Psicologia: teoria e pesquisa, Brasília, DF, v. 25, p. 441-446, 2009.

PANZINI, R.G.; BANDEIRA, D. R. Escala de Coping Religioso-Espiritual (Escala CRE): Elaboração e validação de construto. Psicologia em Estudo, Maringá/PR, v. 10, p. 507-516, 2005.

PARGAMENT, K. I. The psychology of religion and coping. Theory, research, practice. Nova York: The Guilford Press, 1997.

PASSOS, J. D.; USARSKI, F. (Orgs.). Compêndio de ciência da religião. São Paulo: Paulinas e Paulus, 2013.

OLIVEIRA, V. L. et al. Seção temática psicologia e religião. Relegens Threskeía. Curitiba, v. 4, p. 1-147, 2015.

Revista de psicologia normal e patológica, ano XI. [Notícias] do Instituto de Psicologia da PUC-SP e Estatutos da Sociedade Brasileira de Psicologia Religiosa, ano I, p. 203-205, 1965. 
PAIVA, G. J.

RODRIGUES, A. Psicologia da Graça (original de 1937). São Paulo: Loyola, 1983.

THEISSEN, G. Psychologie des premiers chrétiens. Héritages et ruptures. Genebra: Labor et Fides, 2011.

VALLE, E. Psicologia e Experiência religiosa. São Paulo: Loyola, 1998.

VALLE, E. (2015). A formação em Psicologia e a disciplina da Psicologia da Religião: um tema negligenciado? A experiência da PUC-SP no espelho de dois de seus periódicos X Seminário de Psicologia e Senso Religioso, Curitiba, Resumo estendido.

Recebido: 03/11/2016

Received: 11/03/2016

Aprovado: 17/12/2016

Approved: 12/17/2016 